* $\mathrm{O}$ artigo deriva

da dissertação

'Condicionantes do

diagnóstico tardio

do câncer de colo de

útero na perspectiva de

mulheres atendidas no

Inca: contribuições da

abordagem qualitativa',

realizada na Ensp/Fiocruz,

com bolsa Capes.

1 Fundação Oswaldo Cruz (Fiocruz), Escola Nacional de Saúde Pública Sergio Arouca (Ensp) - Rio de Janeiro (RJ), Brasil

rangel.gabriela@gmail.com

2 Fundação Oswaldo Cruz (Fiocruz), Escola Nacional de Saúde Pública Sergio Arouca (Ensp) - Rio de Janeiro (RJ), Brasil

luciana@ensp.fiocruz.br

3 Fundação Oswaldo Cruz (Fiocruz), Instituto Oswaldo Cruz (IOC) - Rio de Janeiro (RJ), Brasil. epvargas@ioc.fiocruz.br

\section{Condicionantes do diagnóstico tardio do câncer cervical na ótica das mulheres atendidas no Inca*}

\author{
Conditioning factors in the late diagnosis of cervical cancer from the \\ perspective of women treated at Inca
}

Gabriela Rangel1, Luciana Dias de Lima², Eliane Portes Vargas $\mathbf{3}$

RESUMO Neste estudo, identifica-se a contribuição de fatores para o diagnóstico tardio do câncer de colo uterino entre mulheres atendidas no Instituto Nacional do Câncer no Rio de Janeiro. Considerou-se as categorias 'acessibilidade' e 'vínculo' na análise das informações, tendo como pressuposto a importância da integralidade como eixo norteador das práticas em saúde. Apoiado na abordagem qualitativa, as estratégias metodológicas incluem a observação direta e entrevistas semiestruturadas. Os resultados sugerem que as concepções e percepções das mulheres em relação à doença e à atenção à saúde e o vínculo destas com os profissionais atuam de modo inter-relacionado, condicionando o acesso aos serviços.

PALAVRAS-CHAVE Avaliação em saúde; Neoplasias do colo do útero; Diagnóstico tardio; Acesso aos serviços de saúde.

\begin{abstract}
This study identifies the contribution of some factors for the late diagnosis of cervical cancer among women treated at the National Cancer Institute in Rio de Janeiro. The categories considered in analyzing the information were 'accessibility' and patient-doctor 'relationship', based on the premise of the importance of comprehensiveness as a guiding principle in health care. A qualitative approach was adopted involving the methods of direct observation and semi-structured interviews. The results suggest that the women's ideas and views regarding the disease and the health care, and their bond with the health care professionals are interrelated and condition access to the services.
\end{abstract}

KEYWORDS Health evaluation; Uterine cervical neoplasms, Late diagnosis; Health services accessibility. 


\section{Introdução}

O câncer configura-se atualmente como um importante problema de saúde pública no cenário nacional e internacional. Estimativas da International Agency for Research on Cancer, da Organização Mundial de Saúde (OMS), sugerem que, em 2030, o número de casos novos da doença chegará a 21,4 milhões, atingindo cerca de 13,2 milhões de óbitos, em consequência do envelhecimento da população, da redução na mortalidade infantil e das mortes por doenças infecciosas em países em desenvolvimento (INCA, 2014). Particularmente, as taxas de incidência do câncer de colo uterino nas mulheres brasileiras estão entre as mais altas do mundo (FIOCRUZ, 2012), sendo o terceiro câncer mais frequente nesse grupo, com uma estimativa de 15.590 casos novos para 2015, ou seja, um risco estimado de 15,33 casos a cada $100 \mathrm{mil}$ mulheres (INCA, 2014).

A forma mais eficaz de controle desse tipo de tumor é através do diagnóstico e tratamento das lesões precursoras e tumorais invasoras em seus estágios iniciais, quando o potencial de cura é expressivo. Nesse sentido, o exame citopatológico (Papanicolau) aumenta as possibilidades terapêuticas na medida em que contribui para o diagnóstico precoce dessas lesões. Em anos recentes, pesquisas demonstraram o papel promissor da vacina contra o HPV (Human Papiloma Virus) para o combate ao câncer do colo do útero, entretanto os resultados indicam que não se pode prescindir das ações de prevenção e de detecção por meio do rastreamento de alterações citológicas em mulheres assintomáticas como estratégias de controle da doença (INCA, 2014).

Tais conhecimentos permitem constatar que a formulação e a implementação de políticas voltadas para a redução da incidência e da mortalidade do câncer de colo uterino podem contribuir para o alcance de resultados efetivos no que tange a mudanças no quadro epidemiológico da doença no País.
No Brasil, ao longo dos anos, foram desenvolvidas diversas ações e estratégias de rastreamento e controle do câncer de colo de útero. Entretanto, somente em 1998, o governo brasileiro reconheceu a necessidade de uma atuação em âmbito nacional, desenvolvendo, por meio do Instituto Nacional do Câncer (Inca), vinculado ao Ministério da Saúde (MS), o Programa Nacional de Rastreamento do Câncer do Colo Uterino - Programa Viva Mulher. Seu objetivo consistia na redução da mortalidade e das repercussões físicas, psíquicas e sociais desse câncer na mulher, por meio da estruturação de uma rede de atenção que visava reduzir a desigualdade de acesso ao rastreamento e tratamento das lesões precursoras com alto potencial de malignidade ou carcinoma in situ (MORAES, 1997).

A partir do Programa Viva Mulher, observou-se uma crescente ampliação da oferta de exames citopatológicos no País, com o aumento de menos de 7 milhões de exames por ano, em 1998, para 10,4 milhões em 2004 (MARTINS; THULER; VALENTE, 2005). Contudo, as ações de prevenção e detecção precoce não tiveram o impacto esperado na redução das taxas de morbimortalidade por câncer do colo do útero no mesmo período.

Em 2005, novas metas e estratégias para o controle do câncer de colo do útero e da mama foram estipuladas no âmbito da Política Nacional de Atenção Oncológica, sendo que, em 2006, tornou-se prioridade do Pacto pela Vida e um compromisso assumido pelas três esferas de governo para a consolidação do Sistema Único de Saúde (SUS). Entre as iniciativas mais recentes voltadas para o aprimoramento das ações específicas de controle do câncer de colo de útero no Brasil, destacam-se: a criação de um grupo de trabalho, em 2010, com a finalidade de avaliar o Programa Nacional de Controle de Câncer de Colo do Útero; a atualização das Diretrizes Brasileiras para o Rastreamento de Câncer do Colo do Útero em 2011; e a inclusão das ações de controle de câncer entre 
os 16 Objetivos Estratégicos do Ministério da Saúde para o período 2011-2015, no que tange à Política Nacional de Prevenção e Controle de Câncer na Rede de Atenção às Pessoas com Doenças Crônicas.

Contudo, a despeito dessas iniciativas, levantamentos recentes sugerem que as propostas para a detecção precoce e controle do câncer de colo de útero no Brasil permanecem com um enfoque programático e restrito, não garantindo a articulação adequada das ações e serviços de rastreamento, investigação diagnóstica, tratamento e acompanhamento das mulheres com lesões sugestivas.

O presente estudo parte do pressuposto de que as avaliações sobre o acesso em uma perspectiva mais ampla podem ajudar no planejamento e na implementação de ações de saúde mais efetivas. Além disso, considera-se que as avaliações das ações de controle do câncer de colo do útero devem também considerar o ponto de vista das mulheres atendidas nos serviços de saúde, aspecto relevante em termos das posições diferenciadas que elas ocupam na estrutura social e institucional que envolve o cuidado à saúde. Portanto, torna-se importante investigar as visões, valores e experiências destes atores, denominados genericamente nos estudos e práticas avaliativas em saúde como usuários dos serviços de saúde, e não apenas as dos gestores e profissionais (BOSI; UCHIMURA, 2010).

Algumas abordagens nessa direção podem ser observadas em estudos recentes. Méndez, Acevedo e Ceballos (2010), por exemplo, apontam que as políticas e os programas de saúde voltados para o controle desse câncer apresentam um baixo impacto, pois desconhecem as percepções, vivências e significados atribuídos pelas mulheres, resultando em estratégias inadequadas de comunicação para promover uma cultura de prevenção e autocuidado. Nesta direção, Cruz e Loureiro (2008) sugerem que uma boa estratégia de envolvimento das mulheres nas ações preventivas, ainda não alcançadas nas campanhas, é tornar os programas de prevenção mais próximos das crenças e valores culturais delas.

Tal discussão suscita algumas indagações, entre as quais a que motivou a realização deste estudo: como aspectos relacionados à acessibilidade e ao vínculo estabelecido entre as mulheres e os serviços de saúde podem contribuir para o diagnóstico tardio do câncer de colo de útero no Brasil? Nessa direção, a pesquisa teve como foco a avaliação dos fatores que intervêm nesses processos na perspectiva das mulheres com estágio avançado da doença, privilegiando-se aspectos subjetivos e culturais e relacionados à organização e às práticas dos serviços de saúde, que interferem no acesso, adesão e continuidade das ações de prevenção do câncer de colo uterino.

\section{Método}

O estudo foi realizado no Inca/Hospital do Câncer II (HC II), na cidade do Rio de Janeiro, em 2010. Caracterizou-se pela abordagem qualitativa, a fim de analisar os fatores condicionantes do diagnóstico tardio do câncer de colo uterino a partir da ótica das mulheres atendidas. Pretendeu-se identificar dois conjuntos de fatores: um de ordem institucional, relacionado à organização e às práticas dos serviços de saúde; outro relativo aos aspectos culturais, modeladores da percepção da doença que interferem no acesso, adesão e continuidade das ações de prevenção do câncer de colo uterino e condicionam a procura de ações e serviços de prevenção e diagnóstico precoce. Tendo em vista esses fatores e suas inter-relações, as categorias 'acessibilidade' aos serviços de saúde e 'vínculo' estabelecido entre profissionais e usuárias dos serviços de saúde foram eleitas como fundamentais na avaliação das ações e estratégias de rastreamento e controle do câncer de colo de útero.

Além disso, adotou-se a perspectiva da avaliação qualitativa de programas de 
saúde, a fim de incluir as demandas subjetivas, percepções, valores, sentimentos e desejos dos atores envolvidos nas ações em saúde (BOSI; UCHIMURA, 2010), imprescindíveis aos objetivos do estudo.

As estratégias metodológicas adotadas foram a observação direta e as entrevistas semiestruturadas (VICTORA; KNAUTH; HASSEN, 2000). O trabalho de campo teve duração de 3 meses e iniciou-se com a observação direta, visando contextualizar as demandas das mulheres por atendimento, seguindo-se da realização das entrevistas semiestruturadas.

As entrevistas foram realizadas com mulheres, atendendo aos seguintes critérios: portadoras de câncer de colo de útero avançado, matriculadas no Hospital do Câncer II (HC II) em 2010 e com indicação de tratamento ambulatorial combinado de radioterapia e quimioterapia, pois estes possibilitariam compreender os fatores concorrentes para o desfecho desses casos extremados. Neste estudo, foi considerado como câncer de colo uterino avançado os casos da doença classificados a partir do estadiamento II B, estabelecido pelas Rotinas do Serviço de Ginecologia do HC II/Inca, nos quais as possibilidades de tratamento são limitadas aumento da probabilidade de complicações, diminuição das chances de cura e sobrevida.

O eixo orientador da análise corresponde à perspectiva da integralidade na organização e nas práticas dos serviços de saúde (MATTOS, 2007), visando privilegiar as percepções e concepções dos usuários nos estudos avaliativos em saúde. Segundo Mattos (2007), a integralidade envolve o desafio de construção de arranjos nos serviços de saúde, que considere o ponto de vista específico dos usuários de modo a colocá-lo no centro das discussões sobre a organização das práticas.

Convergentemente com essa perspectiva, a categoria acessibilidade expressa tanto as características da oferta relacionada ao sistema de saúde quanto as dos indivíduos no que concerne às relações estabelecidas entre eles no uso de serviços de saúde, indicando o grau de ajuste/desajuste entre as necessidades da população e os recursos utilizados (TRAVASSOS; MARTINS, 2004; CAMPOS, 2006). Por outro lado, o vínculo estabelecido entre os usuários e profissionais nos serviços, um dos aspectos que intervêm na acessibilidade, foi destacado como categoria relevante dada a sua importância "para a instituição de uma prática clínica de qualidade" (CAMPOS, 2006, P. 63). Reconhece-se que o estabelecimento de vínculos se encontra também emoldurado pelos atributos dos serviços em termos de oferta de recursos, ultrapassando-o. No entanto, torna-se importante observar, na interação dos usuários com os profissionais, como as mulheres o percebem e, sobretudo, como lidam com as informações visando o acesso à atenção à saúde. Destacou-se, assim, como elementos para avaliação do vínculo, as percepções das mulheres quanto às relações estabelecidas nos serviços de saúde, os significados atribuídos aos cuidados oferecidos, à continuidade dos atendimentos e à satisfação de suas necessidades.

$\mathrm{O}$ estudo atende às determinações das questões éticas em pesquisa (BRASIL, 1996), tendo sido aprovado pelos Comitês de Ética em Pesquisa das instituições envolvidas no estudo através dos protocolos $n^{\circ} 89 / 10$ CEP/Ensp e n ${ }^{\circ}$ 59/10 CEP/Inca. As mulheres entrevistadas foram informadas e assinaram o Termo de Consentimento Livre e Esclarecido (TCLE).

\section{Resultados e discussão}

O grupo da pesquisa foi composto por $9 \mathrm{mu}-$ lheres, maiores de 18 anos e não portadoras de doença mental (quadro 1). A idade das entrevistadas variou de 31 a 76 anos de idade, sendo a maioria natural e residente do Rio de Janeiro. O nível de escolaridade correspondeu a: 2 entrevistadas com ensino médio, 1 com ensino médio e técnico, 3 com ensino fundamental, 1 com ensino fundamental incompleto, 1 apenas com alfabetização e 
1 sem estudo. Quanto ao estado civil, 2 entrevistadas se declararam casadas, 2 viúvas, 4 solteiras e 1 divorciada, sendo que entre estas últimas, apenas uma das mulheres residia sozinha - as demais com companheiros. Ressalta-se que as mulheres, em geral, apresentaram uma efetiva rede de suporte familiar e social, mesmo em situação de ausência de companheiros. A condição socioeconômica - expressa através da renda familiar - variou de 1 a 3 salários mínimos; e as ocupações corresponderam ao trabalho doméstico, do lar, serviços gerais ou técnicos. A situação da doença, no entanto, já provocara, no momento das entrevistas, o afastamento das atividades laborais de 3 entrevistadas.

Quadro 1. Perfil das mulheres entrevistadas na pesquisa

\begin{tabular}{|c|c|c|c|c|c|c|c|c|c|c|}
\hline Entrevistadas & Idade & Naturalidade & Escolaridade & Estado Civil & $\begin{array}{l}\text { Trabalho } \\
\text { atual }\end{array}$ & Moradia & $\begin{array}{l}\text { Com quem } \\
\text { mora }\end{array}$ & Religião & $\begin{array}{l}\text { Renda } \\
\text { Familiar }\end{array}$ & Preventivo \\
\hline M1 & 48 & RJ & $\begin{array}{l}\text { Ensino } \\
\text { Médio }\end{array}$ & $\begin{array}{l}\text { Divorciada } \\
\text { e unida } 22 \\
\text { anos }\end{array}$ & $\begin{array}{l}\text { Não } \\
\text { trabalha } \\
\text { (pela } \\
\text { doença) }\end{array}$ & $\begin{array}{l}\text { Vilar dos } \\
\text { Teles }\end{array}$ & Marido & Evangélica & $\begin{array}{l}\mathrm{R} \$ 600,00 \\
\text { (marido) } \\
+1 \text { salário } \\
\text { mínimo } \\
\text { (INSS) }\end{array}$ & $\begin{array}{l}\text { Realizava } \\
\text { anualmente, } \\
\text { após o parto } \\
\text { da última } \\
\text { filha (adulta e } \\
\text { casada) }\end{array}$ \\
\hline M2 & 34 & RJ & $\begin{array}{l}\text { Ensino } \\
\text { Médio }\end{array}$ & Casada & Do Lar & $\begin{array}{l}\text { Coelho } \\
\text { da Rocha }\end{array}$ & $\begin{array}{l}\text { Marido, } 2 \\
\text { filhos e } 1 \\
\text { enteado }\end{array}$ & Católica & $\begin{array}{l}\text { Bolsa } \\
\text { família + R\$ } \\
800,00 \mathrm{a} \\
\mathrm{R} \$ 1.000,00 \\
\text { (marido) }\end{array}$ & $\begin{array}{l}\text { Último } \\
\text { preventivo há } \\
15 \text { anos* }\end{array}$ \\
\hline M3 & 47 & RJ & $\begin{array}{l}\text { Ensino } \\
\text { Fundamental }\end{array}$ & Solteira & $\begin{array}{l}\text { Não } \\
\text { trabalha } \\
\text { (pela } \\
\text { doença) }\end{array}$ & Nilópolis & Filha & Católica & $\begin{array}{l}1 \text { salário } \\
\text { mínimo }\end{array}$ & $\begin{array}{l}\text { Após } \\
23 \text { anos, } \\
\text { realizava } 1 \text { ou } \\
2 \text { vezes ao } \\
\text { ano }\end{array}$ \\
\hline M4 & 76 & MT & Não estudou & Viúva & $\begin{array}{l}\text { Não } \\
\text { trabalha }\end{array}$ & Agulha & Filha & Evangélica & $\begin{array}{l}1 \text { salário } \\
\text { mínimo }\end{array}$ & $\begin{array}{l}10 \text { anos sem } \\
\text { realizar }^{\star}, \\
\text { mas antes } \\
\text { realizava } \\
\text { regularmente }\end{array}$ \\
\hline M5 & 31 & RJ & $\begin{array}{l}\text { Até o 7ㅇ } \\
\text { ano Ensino } \\
\text { Fundamental }\end{array}$ & Solteira & - & $\begin{array}{l}\text { S. J. de } \\
\text { Meriti }\end{array}$ & $\begin{array}{l}\text { Esposo, } 2 \\
\text { filhos e } 2 \\
\text { filhas }\end{array}$ & Católica & $\begin{array}{l}1 \text { salário } \\
\text { mínimo } \\
\text { (marido) }\end{array}$ & $\begin{array}{l}\text { Realizava } \\
\text { anualmente, } \\
\text { desde os } 15 \\
\text { anos }\end{array}$ \\
\hline M6 & 35 & RJ & $\begin{array}{l}\text { Ensino Médio } \\
\text { e Técnico }\end{array}$ & Solteira & Indústria & Colégio & Filho & $\begin{array}{l}\text { Evangélica, } \\
\text { mas já foi } \\
\text { católica }\end{array}$ & $\begin{array}{l}2 \text { salários } \\
\text { mínimos }\end{array}$ & $\begin{array}{l}10 \text { anos sem } \\
\text { realizar*, } \\
\text { e sem } \\
\text { regularidade } \\
\text { antes disso }\end{array}$ \\
\hline M7 & 56 & RJ & $\begin{array}{l}\text { Ensino } \\
\text { Fundamental }\end{array}$ & Casada & $\begin{array}{l}\text { Não } \\
\text { trabalha } \\
\text { (pela } \\
\text { doença) }\end{array}$ & Magé & $\begin{array}{l}\text { Marido e } 3 \\
\text { filhos }\end{array}$ & Evangélica & $R \$ 640,00$ & $\begin{array}{l}\text { Há } 2 \text { anos } \\
\text { e meio sem } \\
\text { realizar*, mas } \\
\text { anualmente } \\
\text { antes disso }\end{array}$ \\
\hline
\end{tabular}




\begin{tabular}{|c|c|c|c|c|c|c|c|c|c|c|}
\hline \multicolumn{11}{|c|}{ Quadro 1. (cont.) } \\
\hline M8 & 68 & RJ & $\begin{array}{l}\text { Ensino } \\
\text { Fundamental }\end{array}$ & Viúva & Do Lar & Niterói & Sozinha & Espírita & $R \$ 600,00$ & $\begin{array}{l}\text { Há } 3 \text { anos } \\
\text { sem realizar* } \\
\text { e sem } \\
\text { regularidade } \\
\text { antes disso }\end{array}$ \\
\hline M9 & 64 & RS & $\begin{array}{l}10 \text { ano Ensino } \\
\text { Fundamental }\end{array}$ & $\begin{array}{l}\text { União (> de } \\
\text { 30, falecido) } \\
\text { e solteira }\end{array}$ & Do lar & Niterói & $\begin{array}{l}\text { Filha, genro, } \\
\text { e a filha } \\
\text { destes }\end{array}$ & Católica & $\begin{array}{l}1 \text { salário } \\
\text { (INSS), R\$ } \\
700,00, \text { e } \\
R \$ 1.200,00 \\
\text { (filha e } \\
\text { genro) }\end{array}$ & $\begin{array}{l}\text { Há } 2 \text { anos } \\
\text { sem realizar* } \\
\text { e sem } \\
\text { regularidade } \\
\text { antes disso }\end{array}$ \\
\hline
\end{tabular}

Em relação à realização do exame preventivo, 3 entrevistadas informaram realizá-lo anualmente, sendo que uma delas relatou uma frequência de 1 a 2 vezes ao ano; 2 entrevistadas apresentaram um período maior sem a realização do exame - entre 2 anos e meio e 10 anos, mas com regularidade antes deste período; 3 entrevistadas também apresentavam um período maior sem a realização do exame - 2 anos, 3 anos e 10 anos, mas sem regularidade antes deste período; e 1 entrevistada apresentou um período mais expressivo de 15 anos sem a realização do exame preventivo. Por fim, em relação ao quadro da doença, uma das mulheres apresentava um estágio mais avançado que as demais, com dificuldades de locomoção. Neste caso específico, e de forma geral no estudo, a religião se apresentou como instância de grande relevância em suas vidas, por estar relacionada ao significado atribuído à doença e ao enfrentamento da situação de sofrimento gerado pela descoberta do câncer.

Com base nos referenciais teórico-metodológicos adotados, buscou-se apreender dois conjuntos de fatores: (1) caracterizado pela organização do serviço; (2) composto pela descrição de aspectos relevantes das concepções sobre a doença presentes nas relações das usuárias com o serviço de saúde e nas percepções sobre as práticas preventivas. No primeiro conjunto, em que foram consideradas as categorias 'acessibilidade' e 'vínculo' na análise das informações, apontaram-se as dificuldades e os apoios obtidos pelas mulheres no percurso pelos serviços de saúde, bem como as estratégias utilizadas na busca e obtenção de atenção à saúde (TRAVASSOS; MARTINS, 2004). No segundo conjunto, procurou-se aferir as concepções das mulheres sobre o câncer de colo uterino, e seu desenvolvimento, que interferem na decisão quanto à procura e adesão aos programas de prevenção e diagnóstico precoce, tendo em vista os investimentos em propagandas e campanhas de prevenção do câncer em mulheres em idade reprodutiva (CRUZ; LOUREIRO, 2008; MÉNDEZ; ACEVEDO; CEBALLOS, 2010).

\section{Condicionantes da acessibilidade e do vínculo}

Tendo em vista o primeiro conjunto de fatores relacionado à organização dos serviços, as mulheres relataram dificuldades associadas à demora na marcação de consultas e/ou exames; atrasos no atendimento; problemas encontrados para a realização de preventivos relativos à reduzida oferta de serviços e/ou à demora na entrega do resultado (de 3 a 8 meses) e extravio deste; como podem ser observados nos seguintes relatos:

Não tem ginecologista, nunca tem, quando tem é pra marcar daqui há 8 meses mais ou menos, eles fornecem o número, aí você tem que levantar de madrugada, dão 4, 5 números para uma fila 
com mais de 30 pessoas. Muito precário. (M6, 35 anos, Rio de Janeiro, técnica de laboratório, preventivo realizado 1 ou 2 vezes ao ano, desde os 23 anos);

"Meu último preventivo demorou 8 meses, extraviou, fiz em um posto e foi parar em outro posto de outro bairro" (M5, 31 anos, Rio de Janeiro, preventivo realizado anualmente, desde os 15 anos); "Você fica ali toda vida esperando chamar, aí chega um, vai na frente, aí chega outro 'ah, não esse aqui tem que ir na frente"' (M4, 76 anos, Mato Grosso, não trabalha, preventivo não realizado nos últimos 10 anos e regularmente).

Os resultados apontaram para a precariedade dos serviços públicos de saúde - expressa pela carência de recursos humanos, falta de condições e preparo técnicos e superlotação -, evidenciando questões macroestruturais do sistema de saúde, o que dificulta a garantia do acesso igualitário, integral e de qualidade à população. Destacaram-se, ainda, as questões microestruturais da organização dos serviços, nas quais foi possível observar problemas na formalização e cumprimento de regras no processo de atendimento (FLEURY, 2011).

Brito-Silva et al. (2014) relacionam a dificuldade no acesso à atenção básica à baixa flexibilidade no agendamento de consultas, considerando as restrições associadas à dinâmica do atendimento e sua burocratização como complicadores e desestímulo à busca do serviço pelas mulheres, o que resulta no retardo da realização do Papanicolau. Nesse sentido, Parada et al. (2008) sugerem a reorganização da recepção nas Unidades Básicas de Saúde (UBS) mediante implementação de estratégias, tais como: atendimento sem necessidade de agendamento prévio, horários alternativos (noturno ou fim de semana), busca ativa das mulheres na faixa etária do programa, principalmente as que nunca realizaram exame colpocitológico com vistas a ampliar e facilitar o acesso das mulheres a esses serviços.
Destacou-se, ainda, nos relatos, a 'peregrinação’ das usuárias entre as várias unidades de saúde em busca de atendimento, o que evidencia a falta de acolhimento e resolutividade. A 'peregrinação' tem sido observada em diversos estudos recentes sobre o acesso à saúde, estando associada à precariedade dos serviços e às desigualdades no acesso e utilização dos serviços de saúde (FLEURY, 2011). Somado a esse fato, as mulheres demonstraram pouco conhecimento acerca dos locais de atendimento para a realização dos exames preventivos do câncer de colo uterino, sendo que, quando presentes, essas informações tiveram origem no ambiente familiar - repassadas de mãe/ tias para filha/sobrinha.

O Programa Viva Mulher recomenda que os exames preventivos sejam ofertados nas UBS, contudo, as mulheres entrevistadas relataram dificuldades em encontrar o profissional nas unidades para atendimento e realização do exame, como exemplificado no relato a seguir: "Eu acho que tinha que melhorar o atendimento e colocar mesmo ginecologista nos postos. Eu sempre falava isso, '[...] quando a gente vai procurar não tem!'” (M3, 47 anos, Paraty, sem trabalhar por causa da doença, preventivo realizado há 15 anos).

Nessa direção, importantes barreiras parecem ter dificultado a utilização dos serviços de saúde por parte das mulheres com câncer de colo uterino em estágio avançado. Nesse sentido, a falta de informação das mulheres encontra ressonância nas condições concretas relacionadas à oferta de atendimento no sistema de saúde, que encontra limites para sua avaliação no âmbito do presente trabalho. Em termos propositivos, na perspectiva da integralidade, a rede de serviços de saúde deveria responder à necessidade de acesso aos serviços de saúde, sintonizando-se com a dinâmica que estrutura a vida social e considerando a noção do território, na condição dos modos de operação. Isso inclui que os horários sejam compatíveis com as necessidades da população 
adscrita (MATTOS, 2007), o que não foi observado nos dados encontrados. Cabe ressaltar, no entanto, que esses achados se encontram restritos à ótica das mulheres atendidas no Inca. Ainda ponderando sobre ações mais efetivas, a Estratégia Saúde da Família (ESF), por ser um modelo de assistência constituído por equipes responsáveis pelo acompanhamento de um número definido de famílias em uma área geográfica delimitada, poderia favorecer um maior acesso da população ao programa, inclusive por meio da identificação e busca ativa das mulheres elegíveis para o rastreamento e tratamento, o que aumentaria a resolutividade da assistência e, consequentemente, o controle dessa neoplasia (GIRIANELLI; THULER; SILVA, 2014). Todavia, ainda que se considere a especificidade do estudo, não foram mencionados relatos de tal situação entre as mulheres entrevistadas.

Em relação à barreira organizacional, foi identificada, a partir da percepção das mulheres, uma 'lógica própria' de funcionamento dos serviços na qual as recepcionistas exercem uma espécie de triagem para o atendimento, selecionando quem deve ser atendido em primeiro lugar, o que se contrapõe à noção de acesso irrestrito como lógica geral do sistema de saúde preconizado pelo SUS. Segundo as mulheres, essa lógica é justificada por critérios de maior gravidade, porém há entre elas a percepção de que a escolha não é realizada pelo profissional adequado - o médico - e de que ocorrem favoritismos e desrespeito à fila de espera. Observou-se, ainda, o encaminhamento das mulheres para atendimento em ônibus de campanha de exame preventivo do câncer de colo do útero, o que sugere o caráter isolado das ações em saúde, não condizentes com a perspectiva do atendimento integral a partir de um fluxo organizado do cuidado a essas mulheres dentro do sistema de saúde, como propõe o Programa Viva Mulher.

Outras alternativas, no entanto, mostraram-se como facilitadores do acesso à saúde, como, por exemplo, a utilização de mecanismos informais de acesso - através da utilização das relações com trabalhadores da saúde para o acesso, burlando a fila de espera. $\mathrm{Ou}$, ainda, como apontam as entrevistadas, através da realização de um 'escarcéu' ou 'uma rebeliãozinha' nos serviços de saúde - a partir do entendimento de que 'é necessário brigar para ser atendido' -; da realização de ameaças de acesso à mídia ou da utilização de estratégias pessoais, como explicar sua situação à recepcionista, a fim de sensibilizá-la e garantir a indicação de 'urgente' em seus encaminhamentos.

Como alternativas às barreiras na acessibilidade e, muitas vezes, após intensa incursão em variados serviços públicos de saúde, algumas mulheres optaram por pagar consultas e/ou exames particulares ou utilizar planos de saúde privados, como já observado em estudos recentes (SOUSA ET AL., 2008). Tal alternativa utilizada pelas mulheres do estudo esteve relacionada com o fato de que a busca por atendimento ocorreu no momento do aparecimento do sintoma, o que gerou uma situação de urgência, como pode ser observado:

Eu paguei só pra não esperar [...] é melhor se sacrificar e pagar porque irão examiná-las [...] Eu digo a todo mundo 'não vai no posto de saúde, não vai no PAM [Posto de Atendimento Médico] pra fazer preventivo, [...] se puder pagar, paga' (M5, 31 anos, Rio de Janeiro, preventivo realizado anualmente, desde os 15 anos).

O sintoma, nesses casos, determinou a procura por cuidado, levando as mulheres a pagar consultas e exames para acelerar o processo de investigação diagnóstica e posterior tratamento, diante da dificuldade dos serviços públicos de atendê-las prontamente.

No que se refere à relação estabelecida entre as mulheres entrevistadas e os profissionais de saúde encontrados no percurso de acesso aos serviços de saúde, as entrevistadas consideraram que não houve espaço para a escuta das suas percepções e demandas, 
estando presentes atitudes de indiferença no atendimento médico e/ou atitudes consideradas grosseiras por parte dos atendentes e recepcionistas. Como pode ser visto no relato a seguir, as mulheres reivindicaram uma maior atenção por parte dos profissionais de saúde:

Os serviços poderiam ser melhores em relação ao atendimento das pessoas. Só você parar pra conversar... porque tem lugar que você vai e eles não param pra escutar, você está falando e estão virando o rosto. (M7, 56 anos, Rio de Janeiro, não trabalha, preventivo realizado há 2 anos e meio e realizava regularmente).

Além disso, partindo da consciência de que o tempo se constitui em um fator importante para o tratamento do câncer, esteve presente a percepção de que, apesar da gravidade da situação de doença, os médicos não agilizavam os seus encaminhamentos, tornando longa a distância entre as marcações das consultas para investigação diagnóstica. Por outro lado, houve associação da má qualidade na atenção a não identificação da doença, pois, em geral, as mulheres consideraram que as suas queixas iniciais não foram levadas a sério pelos médicos, o que poderia ter ocasionado o diagnóstico tardio. Queixas de diagnósticos errados, situações de negligência, principalmente por parte daquelas que realizavam anualmente o preventivo; assim como insatisfações relacionadas à qualidade do atendimento e dos laboratórios também estiveram presentes. De acordo com os referenciais do estudo (MERHY, 2006; CAMPOS, 2006), esses dados apontam que a expectativa do usuário ao chegar aos serviços de saúde é de acolhimento e resolutividade em relação ao seu problema de saúde e que a ausência observada em relação ao estabelecimento de vínculos entre profissionais e usuários pode implicar em uma menor eficácia, com a diminuição do percentual de curas.

Nesse sentido, o diálogo e a escuta são considerados instrumentos fundamentais do profissional de saúde, devendo estar presentes em todos os momentos do encontro com os usuários. Os profissionais do Programa de Saúde da Família, por exemplo, por estarem mais próximos dos contextos familiares e coletivos, podem construir relações de confiança para discutir as representações sociais/individuais/ culturais sobre a sexualidade e a importância da prevenção do câncer do colo uterino, contribuindo para o controle dessa patologia (OLIVEIRA; PINTO, 2007). Pode-se perceber, no entanto, neste âmbito de atenção ao câncer de colo de útero, que a forma como os serviços de saúde se organizam e estruturam suas práticas parece não privilegiar um espaço adequado para a construção de tais vínculos entre profissionais e usuários, contribuindo para aumentar o distanciamento entre as organizações e os sujeitos atendidos. As condições físicas e organizacionais dificultam o estabelecimento do sigilo, do tempo de consulta necessário para cada paciente, além das frequentes interrupções no atendimento por outros profissionais. Neste contexto, em que se torna necessário problematizar as questões de estrutura e organização dos serviços, e de acordo com a literatura, os profissionais de saúde terminam por não se mostrarem capazes de compreender o sofrimento manifesto do outro e os significados das ofertas de cuidado que se fazem necessárias (MATTOS, 2007).

Em relação aos encaminhamentos médicos, percebeu-se que, em geral, estas ações não expressaram a existência de vínculos entre as mulheres e os profissionais de saúde, no sentido de uma relação de responsabilidade e compromisso entre eles, como presente na literatura (MERHY, 2006). Assim, foram observadas ações malsucedidas, com uma relevante desvinculação dos profissionais em relação ao desdobramento dos encaminhamentos com vistas à efetiva resolução do problema de saúde (MERHY, 2006). Encontraram-se, portanto, nestas interações, 
fatores que condicionam a procura tardia por serviços de saúde.

Destacou-se, no entanto, um relato de um encaminhamento que se coadunou com os pressupostos defendidos neste trabalho: o profissional responsável pelo encaminhamento solicitou que a usuária o informasse acerca do sucesso ou insucesso desta ação. Foi possível perceber que este compromisso com o encaminhamento se relacionou a uma mobilização emocional, devido a uma identificação com a filha desse profissional, que possuía a mesma idade e quadro de doença da entrevistada. Assim, pode-se observar que a possibilidade de um bom desfecho no atendimento parece associar-se também à identificação do profissional de saúde com as situações problemas, significando um rompimento do modo prevalente de operar a relação de atendimento baseada nos binômios dicotômicos 'corpo-doença' e 'corpo-subjetividade'.

Outro dado relevante encontrado diz respeito à coleta de preventivo por profissionais da enfermagem. Apesar de constituir-se em um procedimento usual baseado no treinamento dessas profissionais para tal, percebeu-se que as mulheres não o veem de forma positiva, pois julgam que estas profissionais não são capazes de realizar o procedimento, embora considerem um atendimento acolhedor. Tais dados mostram-se relevantes, pois, ao envolverem a credibilidade dada aos profissionais e aos serviços - e a possibilidade de construção de vínculos -, constituem-se em fatores que interferem no processo de busca e continuidade de cuidados.

Observou-se, por fim, que algumas mulheres realizavam o exame preventivo anualmente, o que corresponde a uma periodicidade maior do que o preconizado pelo Ministério da Saúde no País: a realização do Papanicolau a cada três anos, após dois exames normais consecutivos realizados com um intervalo de um ano. Contudo, o fato de estarem continuamente nos serviços de saúde não foi indicativo do estabelecimento de vínculos com os profissionais de saúde, ao contrário, a relação entre as mulheres entrevistadas e os profissionais mostrou-se uma relação geradora de não acolhimento e não vínculo (MERHY, 2006). Nesse sentido, concorda-se com Merhy (2006) acerca da importância da construção de vínculos que permitam a reconstrução da dignidade de profissionais e pacientes no campo das ações de saúde.

\section{Concepções sobre o câncer de colo de útero e seu desenvolvimento}

No segundo conjunto de fatores, no que concerne às concepções sobre o câncer de colo de útero e seu desenvolvimento, observou-se uma associação direta do câncer com doença incurável, decomposição do corpo vivo e morte, em que estiveram presentes sentimentos de pavor intenso, como demonstrado nos relatos seguintes:

Eu tinha tanto medo, tanto medo, que eu falava assim: se um dia eu descobrir, alguém falar que eu tenho câncer, eu vou morrer antes de chegar no hospital e fazer o tratamento, porque eu tenho pavor, só de saber, eu vou morrer rapidinho. (M4, 76 anos, Mato Grosso, não trabalha, preventivo realizado há 2 anos e sem periodicidade regular);

"Para o câncer, não tem jeito" (M6, 35 anos, Rio de Janeiro, trabalha no setor industrial, preventivo realizado há 10 anos e sem regularidade); "Eu estava podre em vida" (M4, 76 anos, Mato Grosso, não trabalha, preventivo realizado há 2 anos e sem periodicidade regular).

Corroborando estes dados, em estudos relacionados ao tema, o câncer ainda se mostra revestido de conotações negativas e estigmas, sendo representado pelas suas consequências trágicas como a iminência 
da morte (OLIVEIRA; PINTO, 2007). Esses dados mostram também a forte associação da doença à morte em detrimento da cura nos meios de comunicação, o que tende a aumentar o temor nas mulheres. Para as entrevistadas, a palavra 'câncer' em si mesma contém o pavor da doença, tornando-se difícil pronunciá-la ou preferindo-se pronunciá-la em tom de voz mais baixo, em uma tentativa de ocultação. O medo e a negação do câncer constituem um aspecto importante para a compreensão das atitudes das mulheres diante dos serviços, pois, por estarem diretamente associadas à revelação do diagnóstico, tais experiências podem contribuir de forma significativa para o adiamento de busca por atenção. Aliados a esses aspectos subjetivos, encontrou-se o reduzido conhecimento em relação à patologia, seus fatores de risco e suas formas de prevenção, que também se mostraram relacionados à baixa procura por parte dessas mulheres aos serviços de saúde, corroborando estudos sobre o tema (FERREIRA; OLIVEIRA, 2006).

Pesquisas mostram que há uma ampla gama de motivos relacionados a não realização do exame preventivo. Nesse sentido, encontrou-se, no presente estudo, a ausência da prática preventiva na vida das mulheres entrevistadas, devido às atividades do cotidiano - trabalho e afazeres socialmente valorizados -, apesar do conhecimento de que o câncer de colo uterino poderia ter sido evitado com a realização do preventivo. $\mathrm{O}$ grande número de afazeres diários socialmente vistos como necessários e associados às atribuições femininas como mães, donas de casa e trabalhadoras termina por adiar o autocuidado (FERREIRA; OLIVEIRA, 2006).

Além disso, outros fatores motivaram a não realização do preventivo, tais como: o temor do próprio ambiente médico e aspectos culturais, como vergonha, vinculados à realização do exame, como demonstrado nos relatos a seguir:

No meu caso não era nem medo do preventivo, era o pavor que eu tinha de entrar em qualquer hospital, quando eu sentia aquele cheirinho de éter, aquele médico passando de branco perto de mim, aquela enfermeira passando me dava tontura, um negócio ruim, eu ficava apavorada, então, eu evitava ao máximo ir ao médico. (M1, 48 anos, São João de Meriti, sem trabalhar por causa da doença, preventivo realizado há 10 anos).

"Tinha vergonha, e ainda tenho, eu não estava acostumada com isso, fui criada na roça, no meu tempo, os filhos da gente nasciam em casa" (M3, 47 anos, Paraty, sem trabalhar por causa da doença, preventivo realizado há 15 anos).

Eu falava para os meus filhos que nunca ia fazer isso, deixo do jeito que for, não vou mesmo, pela vergonha, porque as pessoas de antigamente só abriam a perna para ter filho e nada mais. (M4, 76 anos, Mato Grosso, não trabalha, preventivo realizado há 2 anos e sem periodicidade regular).

O exame que possibilita a prevenção e o diagnóstico precoce relaciona-se com uma exposição do corpo feminino muito maior que em outras doenças, como o câncer de mama, por exemplo. A produção acadêmica relativa ao tema demonstra que se submeter ao Papanicolau suscita sentimentos de vergonha, medo, nervosismo, constrangimento, ansiedade e dor (SOUSA ET AL., 2008), relacionando tais sentimentos a dificuldades no controle do câncer de colo uterino (CRUZ; LOUREIRO, 2008). Assim como sentimentos de constrangimento e vergonha no que se refere à posição e ao toque ginecológico, e sensações de impotência, desproteção e perda do domínio sobre o próprio corpo induzidos pela posição ginecológica (SOUSA ET AL., 2008).

Dessa forma, é importante que os programas e serviços de saúde se aproximem dessa problemática, compreendendo amplamente os motivos da não realização do exame preventivo, a fim de garantir a efetividade das ações de controle do câncer. Nesse sentido, atitudes e posturas dos profissionais de saúde, expondo apenas a parte do corpo necessária à realização do exame, evitando o trânsito desrespeitoso 
de profissionais na sala de exame e encorajando a mulher a diminuir o medo e a vergonha, fazem diferença, pois o sentimento de vergonha exacerbado pode dificultar o relaxamento e provocar a contração da musculatura pélvica, ocasionando, assim, mais dor e dificultando a realização do exame (FERREIRA; OLIVEIRA, 2006). Além disso, explicar o procedimento ao qual a paciente vai ser submetida e a importância da sua realização gera empatia e confiança entre quem assiste e é assistido (SOUSA ET AL., 2008), facilitando a realização do exame.

A mídia televisiva ou as campanhas, por outro lado, foram referidas pelas entrevistadas como importantes para aguçar a conscientização sobre o tema e tornar a prevenção uma prática em suas vidas, mas apesar da associação entre o diagnóstico precoce e a cura da doença estar presente em seu discurso, observou-se grande inconsistência entre conhecimento e prática: muitas mulheres parecem ter adquirido conhecimentos e atitudes favoráveis sobre prevenção, mas estes não foram incorporados no cotidiano do cuidado à própria saúde (FERREIRA; OLIVEIRA, 2006). Nesse sentido, estudos mostram a relativa importância da informação e do conhecimento na adoção de comportamentos preventivos, pois as informações se integram nos complexos conjuntos constituídos pelas representações, que agem como filtros pelos quais os indivíduos interpretam, aceitam ou rejeitam as novas informações (ADAM; HERZLICH, 2001).

Ainda no incentivo à ação preventiva, no que tange à produção dos significados tendo em vista o sentimento de proximidade com a doença decorrente do conhecimento de pessoas doentes na rede de relações sociais, também estes não se mostraram determinantes na prevenção da doença. Na narrativa das mulheres, a referência a parentes acometidos por câncer, anteriormente à própria doença das entrevistadas, não indicou uma maior preocupação em relação à prevenção, mas sim um aumento do pavor da doença associada à morte do ente familiar. No entanto, posteriormente ao diagnóstico de câncer, uma preocupação com o desenvolvimento da doença na filha esteve presente.
Portanto, é importante não reduzir a atitude preventiva a uma questão de aumento de consciência da importância do exame e/ou dos conhecimentos sobre a doença, mas compreender a existência de um conjunto de fatores ligados a esta questão, relativos à valorização dos afazeres do cotidiano, bem como aos valores, sentimentos e estilos de vida sobrepostos à adoção de práticas preventivas que interferem em seu resultado.

A rede familiar e social, por fim, desempenhou um papel importante no auxílio e incentivo à busca do tratamento, sobretudo no momento do aparecimento dos sintomas e nas situações de não percepção da gravidade por parte da mulher. Até mesmo no período de definição do diagnóstico e da terapêutica, foram observadas ajudas financeiras, acompanhamento às consultas e exames, resolução de documentações, busca de resultados de exames, auxílio nas tarefas domésticas, apoios emocionais e religiosos. $\mathrm{O}$ apoio do cônjuge também se mostrou significativo tendo em vista sua participação na identificação dos sintomas, já que estes ocorreram, muitas vezes, durante ou após as relações sexuais. Nesse sentido, sugere-se uma atenção maior às estratégias de comunicação utilizadas nas campanhas relativas ao câncer de colo uterino, pois elas não contemplam os homens, que, como visto, não estão totalmente ausentes nessa problemática: do ponto de vista das mulheres entrevistadas, muitas vezes, são eles que as estimulam a buscar o tratamento, ainda que a partir dos sintomas.

\section{Conclusão}

Vários fatores condicionam a busca tardia das mulheres ao atendimento ao câncer de colo uterino, entre eles, aqueles relacionados à acessibilidade, na qual se incluem os problemas relativos à disponibilidade e integração de ações e serviços, à história de vida, sentimentos, valores e costumes dessas mulheres, que as distanciam das práticas preventivas; assim como fatores relacionados à fragilidade dos 
vínculos estabelecidos entre as mulheres e os profissionais de saúde, que podem diminuir a capacidade de resposta dos serviços e dificultar a continuidade do cuidado. Na prática dos serviços de saúde, esses fatores atuam de modo inter-relacionado, facilitando ou dificultando a busca e obtenção da atenção e cuidado à saúde por parte das mulheres.

Os resultados do estudo sugerem a importância de pensar e avaliar a organização dos serviços e das práticas de saúde com vistas a um atendimento integral e de qualidade, a partir de relações que possibilitem a busca, o acesso e a continuidade do cuidado.

Além disso, as estratégias de comunicação utilizadas também merecem uma atenção, pois existe uma reduzida visibilidade para o câncer de colo uterino, apesar das suas altas taxas de incidência e mortalidade. A campanha do Programa Viva Mulher, por exemplo, se apoia em mensagens que reforçam alguns valores historicamente construídos em relação à sexualidade feminina, fragilizando as mulheres e responsabilizando-as por suas práticas sexuais e cuidados com o seu corpo,

\section{Referências}

ADAM, P.; HERZLICH, C. Sociologia da doença e da Medicina. Bauru: EDUSC, 2001.

BOSI, M. L. M.; UCHIMURA, K. Y. A. Avaliação qualitativa de programas de saúde: contribuições para propostas metodológicas centradas na integralidade e na humanização. In: BOSI, M. L. M.; MERCADO, F. J. Avaliação Qualitativa de Programas de Saúde. Petrópolis: Vozes, 2010.

BRASIL. Ministério da Saúde. Conselho Nacional de Saúde. Resolução 196 de 10 de outubro de 1996. Brasília, DF: Diário Oficial da República Federativa do Brasil, 1996. Disponível em: <http://bvsms.saude.gov.br/ bvs/saudelegis/cns/1996/res0196_10_10_1996.html>. Acesso em: 17 set. 2015.

BRITO-SILVA, K. et al. Integralidade no cuidado ao câncer do colo do útero: avaliação do acesso. Revista de Saúde Pública da USP, São Paulo, v. 48, n. 2, p. 240-248, abril 2014. além de não contemplarem os parceiros, o que gera um obstáculo, considerando as questões culturais e históricas ligadas à identidade feminina envolvendo a relação com os parceiros. A doença, portanto, apresenta-se escondida, seja pelas associações com a sexualidade, seja pelo perfil de mulheres acometidas, que corresponde a mulheres de baixo nível socioeconômico. Nesse sentido, as campanhas não encontram ressonância no grupo de mulheres mais atingidas pela doença. Por fim, a perspectiva adotada neste estudo traz como contribuição a possibilidade de ampliação do espectro de visão e de compreensão do problema, visando somar esforços na construção de novas estratégias que possam, de fato, diminuir o quadro de morbimortalidade da doença no País.

\section{Agradecimentos}

Agradecimentos a Aurélia Rocha e Andrea Oliveira pelo apoio institucional na realização do trabalho de campo.
CAMPOS, G. W. S. Considerações sobre a arte e a ciência da mudança: revolução das coisas e reforma das pessoas. O caso da Saúde. In: CECÍLIO, L. C. O. (Org.). Inventando a mudança na saúde. 3 ed. São Paulo: HUCITEC, 2006.

CRUZ, L. M. B.; LOUREIRO, R. P. Comunicação na abordagem preventiva do câncer do colo do útero: importância das influências histórico-culturais e da sexualidade feminina na adesão às campanhas. Saúde e Sociedade, São Paulo, v. 17, n. 2, p. 120-131, 2008.

FERREIRA, M. L. M.; OLIVEIRA, C. Conhecimento e significado para funcionárias de indústrias têxteis sobre prevenção do câncer do colo-uterino e detecção precoce do câncer da mama. Revista Brasileira de Cancerologia, Rio de Janeiro, v. 52, n. 1, p. 5-15, 2006.

FLEURY, S. Desigualdades injustas: O contradireito à saúde. Psicologia \&t Sociedade, Florianópolis, v. 23, n. spe, p. 45-52, 2011. 
GIRIANELLI, V. R.; THULER, L. C. S.; SILVA, G. A. Adesão ao rastreamento para câncer do colo do útero entre mulheres de comunidades assistidas pela Estratégia Saúde da Família da Baixada Fluminense, Rio de Janeiro, Brasil. Revista Brasileira de Ginecologia e Obstetrícia, Rio de Janeiro, v. 36, n. 5, p. 198-204, maio 2014.

INSTITUTO NACIONAL DE CÂNCER (INCA). Estimativa 2014: incidência de câncer no Brasil. Rio de Janeiro: Inca, 2014.

MARTINS, L. F. L.; THULER, L. C. S.; VALENTE, J. G. Cobertura do exame de Papanicolaou no Brasil e seus fatores determinantes: uma revisão sistemática da literatura. Revista Brasileira de Ginecologia e Obstetrícia, Rio de Janeiro, v. 27, n. 8, p. 485-492, 2005.

MATTOS, R. A. Repensando a organização da rede de serviços de saúde a partir do princípio da integralidade. In: PINHEIRO, R., MATTOS, R. A. (Org.). Razões públicas para a integralidade em saúde: o cuidado como valor. Rio de Janeiro: CEPESC: IMS: UERJ: Abrasco; 2007. p. 369-383.

MÉNDEZ, M. G. C.; ACEVEDO, L. S. T.; CEBALLOS, A. C. A. Percepción de mujeres de Colima-México y Medellín-Colombia sobre el câncer cervicouterino: causas, prevención y cuidado. In: CONGRESSO IBEROAMERICANO DE CIÊNCIA, TECNOLOGIA E GÊNERO, 8 abril de 2010, Curitiba, Brasil.

MERHY, E. E. Em busca da qualidade dos serviços de saúde: os serviços de porta aberta para a saúde e o modelo tecnoassistencial em defesa da vida (ou como aproveitar os ruídos do cotidiano dos serviços de saúde e colegiadamente reorganizar o processo de trabalho na busca da qualidade das ações de saúde). In: CECÍLIO, L. C. O. (Org.). Inventando a mudança na saúde. 3. ed. São Paulo: Hucitec, 2006.
MORAES, M. F. Programa Viva Mulher. Revista Brasileira de Cancerologia, Rio de Janeiro, v. 43, n. 2, p. 103-105, 1997.

OLIVEIRA, M. M.; PINTO, I. C. Percepção das usuárias sobre as ações de Prevenção do Câncer do Colo do Útero na Estratégia Saúde da Família em uma Distrital de Saúde do município de Ribeirão Preto, São Paulo, Brasil. Revista Brasileira de Saúde Materno Infantil, Recife, v. 7, n. 1, p. 31-38, jan./mar. 2007.

PARADA, R. et al. A política nacional de atenção oncológica e o papel da atenção básica na prevenção e controle do câncer. Revista de Atenção Primária à Saúde, Juiz de Fora, v. 11, n. 2, p. 199-206, abr./jun. 2008.

SOUSA, I. G. S. et al. Prevenção do câncer de colo uterino: Percepções de mulheres ao primeiro exame e atitudes profissionais. Revista da Rede de Enfermagem do Nordeste, Fortaleza, v. 9, n. 2, p. 38-46, abr./jun. 2008.

TRAVASSOS, C.; MARTINS, M. Uma revisão sobre os conceitos de acesso e utilização de serviços de saúde. Cadernos de Saúde Pública, Rio de Janeiro, v. 20, supl. 2, p. 190-198, 2004.

VICTORA, C. G.; KNAUTH, D. R.; HASSEN, M. N. A. Pesquisa qualitativa em saúde: uma introdução ao tema. Porto Alegre: Tomo Editorial, 2000.

\footnotetext{
Recebido para publicação em abril de 2015

Versão final em setembro de 2015

Conflito de interesses: inexistente
}

Suporte financeiro: não houve 